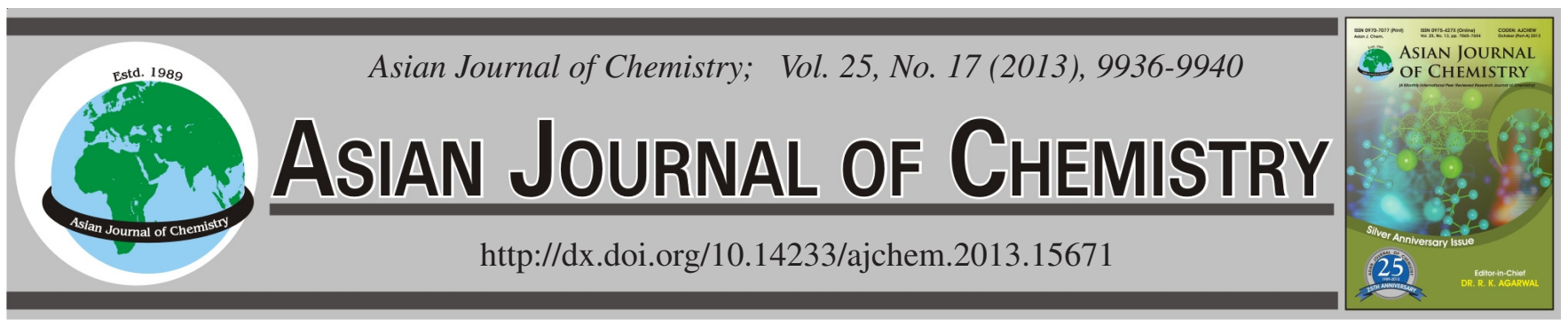

\title{
Preparation and Evaluation of Alginate-Chitosan-Bentonite Based Beads for the Delivery of Pesticides in Controlled-Release Formulation
}

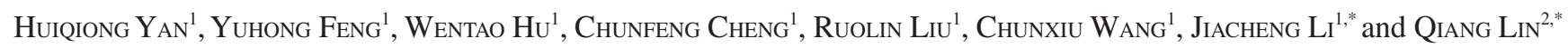

${ }^{1}$ College of Materials and Chemical Engineering, Hainan University, Haikou 570228, P.R. China

${ }^{2}$ Hainan Normal University, Haikou 571100, Hainan, P.R. China

*Corresponding authors: Fax: +86 898 66187313; Tel: +86 898 66275138; E-mail: linqiang1962@ gmail.com

(Received: 23 April 2013;

Accepted: 28 October 2013)

AJC-14309

\begin{abstract}
The alginate-bentonite (SA-BT) bead, sodium alginate (SA) bead, alginate-chitosan (SA-CS) bead and alginate-chitosan-bentonite (SABT-CS) bead were prepared by extrusion into calcium chloride solution and characterized by FT-IR, SEM, thermogravimetry, water-up tests and release studies. Experimental results showed that the obtained hydrogel beads were 1.42-1.71 mm in diameters. Bentonite could improve the hydrogel beads' size and sphericity and make the drug loading rate and encapsulation efficiency of acetamiprid rise up from 4.16 and $36.36 \%$ to 4.91 and $63.01 \%$, respectively. Chitosan and sodium alginate had formed the polyelectrolyte complexes by electrostatic interactions and made the drug loading rate and encapsulation efficiency of acetamiprid rise up from 4.16 and $36.36 \%$ to 5.23 and 54.29 $\%$, respectively. Bentonite contains a lot of hydroxyl groups on the surface that could form the hydrogen bonds with the sodium alginate and chitosan, which could effectively inhibit calcium alginate large swelling to improve the performance of their release.

Key Words: Sodium Alginate, Bentonite, Chitosan, Composite bead, Encapsulation efficiency.
\end{abstract}

\section{INTRODUCTION}

Controlled-release $(\mathrm{CR})$ pesticide formulation, which is based on the amount, the time and the space of release, has an important potential in reducing the consumption and effect of pesticides on the environment ${ }^{1}$. It can prolong the pesticide's activity $^{2}$, reduce the loss of pesticide by leaching ${ }^{3}$, evaporation and degradation ${ }^{4}$ and minimize the danger of percutaneous poisoning ${ }^{5}$. Such pesticide formulations are usually prepared by using natural polymer materials such as sodium alginate and chitosan as the capping agents.

Generally, natural polymers are preferred to prepare pesticidal carrier polymers because of their low cost, free availability, non-toxicity and biodegradation ${ }^{6,7}$. However, the single alginate as matrixs to prepare controlled-release ${ }^{8-11}$ pesticides has its inherent drawbacks, such as poor mechanical strength, uncontrolled degradation and extensive water uptake properties which can result in uncontrolled and unpredicted release rates of the active pesticides ${ }^{12}$. These problems can be minimized by blending with other polymers ${ }^{13-15}$ or with incorporating clays ${ }^{16}$. Clay minerals are usually used as the adsorbents in polymer to slow down the release of pesticides ${ }^{17}$.

In this paper, the drug-loaded composite beads are composed of original pesticides, bentonite and other polymer materials. The pesticides are encapsulated in the three-dimensional mesh structure of beads. Based on that, these beads are considered as a kind of hydrogel. The polymer materials of beads are suitable for controlled-release formulation ${ }^{18}$ due to their good biological compatibility, bioactivity ${ }^{19}$, the viscosity, the film feature, drug-loading capability and degradability. The use of sodium alginate hydrogel with efficient original pesticide for the preparation of slow release formulations can not only prevent the degradation and water erosion of pesticides but also delay the release, prolong efficient duration and reduce the consumption of pesticides ${ }^{2-4}$ which is of vital importance for the effective use of pesticides, environmental protection, water conservation and soil improvement ${ }^{20}$.

The objective of the present work is to take the method ${ }^{21}$ discussed earlier to produce the drug-loaded composite beads with best performance, which have a large load capacity, good release and excellent mechanical properties. The beads will be characterized by FTIR, SEM, TGA, water uptake tests and release studies. Our goal is to explore the interactions of the components on the release performance of the composite beads.

\section{EXPERIMENTAL}

The polymer sodium alginate (specifications: $\mathrm{CP}, \mathrm{M}_{\mathrm{W}}=$ $430 \mathrm{kda}$, viscosity of $1 \%, 2{ }^{\circ} \mathrm{C}: 200 \pm 20 \mathrm{mPa} . \mathrm{s}$ ) and chitosan (CS) (specications: $\mathrm{M}_{\mathrm{w}}=1000 \mathrm{kda}$, viscosity of $1 \%$ solution 
in $1 \% \mathrm{AcOH}$ : $180 \mathrm{mPa} . \mathrm{s}$, deacetylation degree $\geq 95 \%$ ) were purchase from Aladdin, Shanghai. The clay materials bentonite (BT), gellant calcium chloride and acetic acid were also purchased from Aladdin, Shanghai. HPLC grade solvents were purchased from Sigma, China. All other solvents and materials used were of analytical grade.

Preparation of the composite beads: The composite beads were prepared by a modification of the reported method by Singh et $a l^{21}$. This method were based on the gelling properties of the alginate in the presence of divalent cations and the interactions between the carboxyl groups of alginate and the amine groups of chitosan (Fig. 1). Briefly, the measured amount of sodium alginate, bentonite and acetamiprid were dispersed in $50 \mathrm{~mL}$ hot water and the resulting mixture was vigorously stirred to form a homogenous solution. Then this homogenous solution was dropwise added, via a $25 \mathrm{~mL}$ syringe, into a $100 \mathrm{~mL}$ gellant bath of $0.25 \mathrm{M} \mathrm{CaCl}_{2}$, which contained $2 \%(\mathrm{w} / \mathrm{v})$ chitosan in $2 \% \mathrm{AcOH}$ solution, under constant stirring. $0.5 \mathrm{~h}$ later, the beads were formed. Then they were filtered and allowed to dry first at room temperature and then in an oven $\left(40{ }^{\circ} \mathrm{C}\right)$ to constant weight. Beads of different formulations were prepared and its reaction parameters are presented in Table-1.

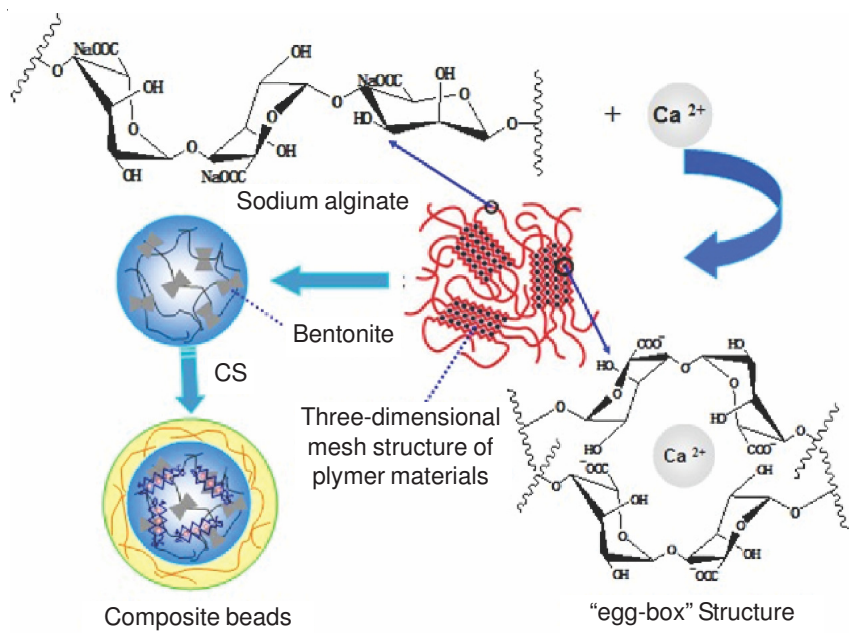

Fig. 1. Schematic diagram for the preparation of the SA-BT-CS beads

Measurement of composite beads size: The size of the composite beads were obtained by measuring twenty completely dried beads from each formulation with $20 \mathrm{~cm}$ Vernier Calipers and then taking their mean value.

Characterization of the composite beads: The composite beads were characterized by fourier transform infrared spectroscopy (FTIR), scanning electron micrograph (SEM) and thermogravimetry(TG). The samples recorded with a Bruker T27 FTIR spectrophotometer were prepared by processing compressed semitransparent $\mathrm{KBr}$ plates before the measurement. SEM was taken by using Hitachi S-3000N scanning electron micrograph after fixing the samples on a brass holder and sputtering them with gold. Thermogravimetric analysis was carried out on a TA Q600 Thermal Analyzer in air at a heating rate of $20^{\circ} \mathrm{C} / \mathrm{min}$ to examine the thermal properties of the samples.

Water uptake tests: The water uptake for the dried beads was measured by the method of Franson and Peppas ${ }^{22} .0 .5 \mathrm{~g}$ completely dried beads were immersed in water of the stoppered conical flasks. Then, they were removed periodically. The excess water was wiped out from the surface of the beads by using filter paper before the beads were weighed. Three replicates were carried out. So the water uptake (g/g dry beads) could be presented with the swelling ratio (SR) of beads calculated as follows:

Swelling ratio (SR)

$$
=\frac{\text { Swelling beads }(\mathrm{W})-\text { Dried beads }(\mathrm{W})}{\text { Dried beads }(\mathrm{W})}
$$

Loading of pesticides: The drug loading is that the pesticides were dispersed in alginate solution and then entrapped into the beads under the action of the gelling agent. Surely a certain quantity of pesticides has been loaded into the beads whereas there are some pesticides left in gellant solution which could be measured by HPLC. If the beads mass has been weighed, the drug loading rate (DL) and encapsulation efficiency (EE) could be calculated as follows:

Drug loading rate (DL)

$$
=\frac{\text { Total pesticides }- \text { Left pesticides }}{\text { Total pesticides }}
$$

Encapsulation efficient (EE)

$$
=\frac{\text { Total pesticides }- \text { Left pesticides }}{\text { Beadsmass }}
$$

Release studies: An accurately weighed quantity of dried composite beads containing about $15 \mathrm{mg}$ acetamiprid was added to $100 \mathrm{~mL}$ of $50 \%$ methanol solution in the stopper conical flask. This system was placed in a constant temperature environment. At different time intervals, a portion of $1 \mathrm{~mL}$ solution was removed for the determination of acetamiprid by HPLC. Three replicates were carried out and the unused sample portions are returned to the flasks.

\section{RESULTS AND DISCUSSION}

FTIR analysis: From the FTIR spectrum of Fig. 2, it is clear that the composite beads spectrum was similar to the bentonite spectrum. The bentonite was mechanically mixed in the matrix of the composite beads. The strong and broad

TABLE-1

REACTION PARAMETERS FOR THE PREPARATION OF THE COMPOSITE BEADS

\begin{tabular}{cccccccc}
\hline $\begin{array}{c}\text { Formulation } \\
\text { code }\end{array}$ & $\begin{array}{c}\text { Alginate } \\
(\% \mathrm{~m} / \mathrm{v})\end{array}$ & $\begin{array}{c}\text { Bentonite } \\
(\% \mathrm{~m} / \mathrm{v})\end{array}$ & $\begin{array}{c}\text { Chitosan } \\
(\% \mathrm{~m} / \mathrm{v})\end{array}$ & $\begin{array}{c}\text { Acetamiprid } \\
(\mathrm{mg})\end{array}$ & $\begin{array}{c}\text { Crosslinker } \\
\text { conc. }(\mathrm{M})\end{array}$ & $\begin{array}{c}\text { Beads formed } \\
(\mathrm{g})\end{array}$ & $\begin{array}{c}\text { Bead diameter } \\
(\mathrm{mm})\end{array}$ \\
\hline SA-C1 & 2 & 2 & - & 200 & 0.25 & 2.57 & $1.69 \pm 0.24$ \\
SA-C2 & 2 & - & - & 200 & 0.25 & 1.75 & $1.42 \pm 0.22$ \\
SA-C3 & 2 & - & 1 & 200 & 0.25 & 2.07 & $1.53 \pm 0.21$ \\
SA-C4 & 2 & 2 & 1 & 200 & 0.25 & 2.78 & $1.71 \pm 0.25$ \\
\hline
\end{tabular}




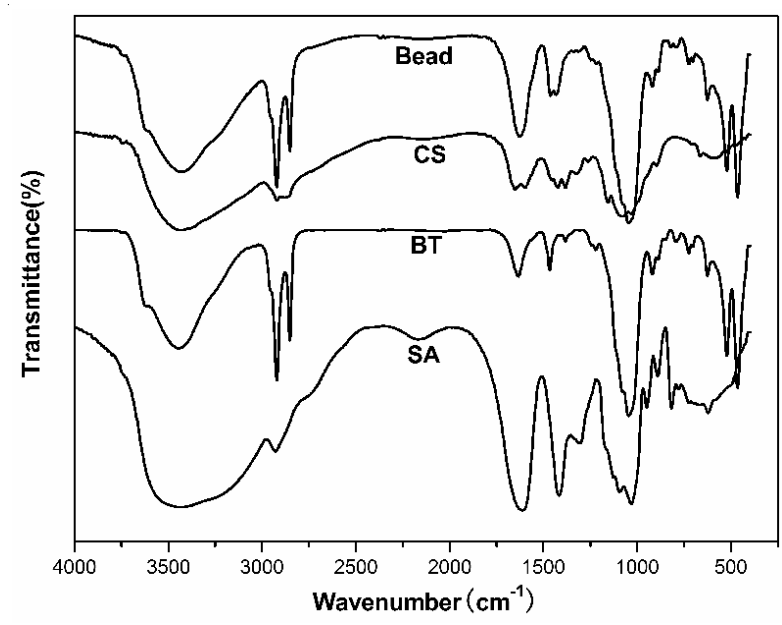

Fig. 2. FTIR spectra of (1) the composite beads, (2) sodium alginate, (3) bentonite and (4) chitosan

absorption band between 4000 and $3000 \mathrm{~cm}^{-1}$ was observed in all samples due to $-\mathrm{OH}$ stretching mode ${ }^{17}$. Two absorption peaks at 1612 and $1416 \mathrm{~cm}^{-1}$ in the sodium alginate spectrum were assigned to asymmetric and symmetric stretching vibrations of carboxyl groups ${ }^{23}$ which shifted to 1628 and $1462 \mathrm{~cm}^{-1}$ in the beads spectrum, respectively. The absorption peaks at 1651 and $1598 \mathrm{~cm}^{-1}$ can be attributed to the stretching of the C-N in the chitosan spectrum. And the peaks at 1090 and $1030 \mathrm{~cm}^{-1}$ were assigned to $-\mathrm{NH}_{2}$ stretching vibrations disappeared in the beads spectrum. These results revealed that the bentonite contains a lot of hydroxyl groups on the surface and the carboxyl of ionized sodium alginate and the amino of chitosan were protonated under acidic conditions. The gelling of the composite beads could be accounted for sodium alginate in the presence of $\mathrm{Ca}^{2+}$ and the interaction between the ionized carboxyl group of sodium alginate and the protonated amino group of chitosan.

CR formulations morphology: As shown in Fig. 3(a) row of the figure presented the photos of the undried beads prepared by four kinds of formulations. They have regularly spherical shapes and uniform sizes with diameters of $1.42 \pm$ $0.22-1.71 \pm 0.25 \mathrm{~mm}$. The sizes of beads depended on the size of the droplets and the sodium alginate beads sizes were the smallest, but their sizes were significantly increased when added bentonite. There was a few size difference between SA$\mathrm{C} 1$ and SA-C4; it was also for SA-C2 and SA-C3. That might be due to the hydrophilic nature of sodium alginate and chitosan, resulting in a large number of dehydration after drying. (b) row of the figure revealed the scanning electron micrographs of the beads at 50 times magnification. The beads exhibited spherical shell with collapsed morphology due to a large number of dehydration. (c) row of the figure showed SEM at 2000 times magnication. SA-C1 and SA-C4 revealed the lamellar structure for the beads containing bentonite. Compared with SA-C2, SA-C3 showed seems rough and exhibits crumpled shape because of the film-forming feature and hydrophilicity of chitosan. There were many pores inside the beads that could be seen from their cutting plane (Fig. 4), which were determined by the gel method. The gelling of the beads always started from the outer layer. The outer gelling density could retard the further gelling of inner layer.
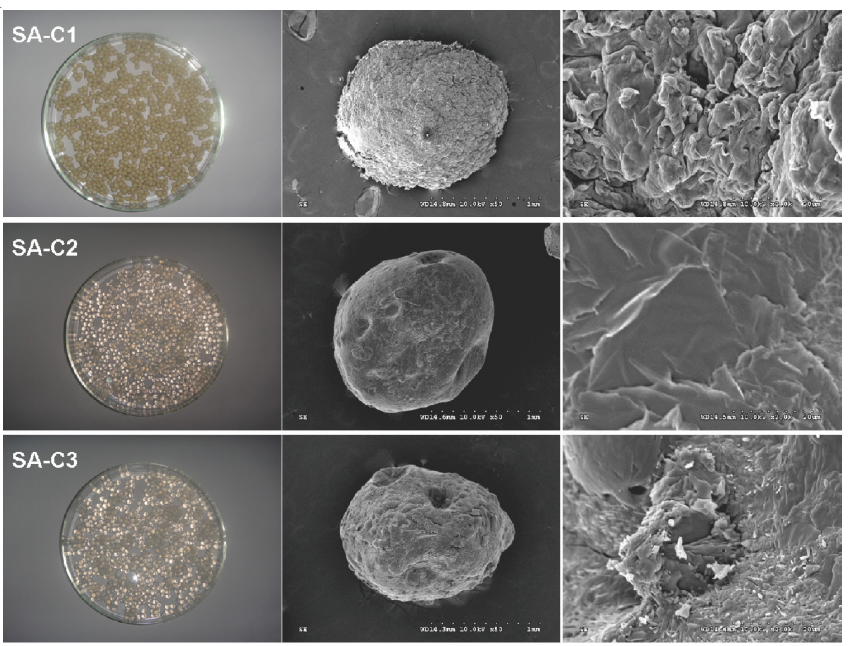

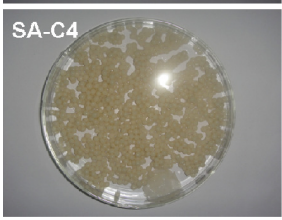

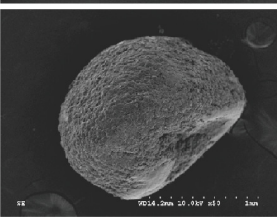

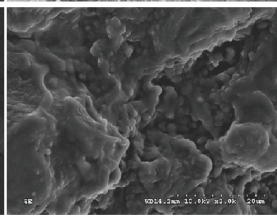

Fig. 3. (a) row shows the photos of the undried SA-BT beads (SA-C1), the undried sodium alginate beads (SA-C2), the undried SA-CS beads (SA-C3) and the undried SA-BT-CS beads (SA-C4). (b) and (c) row show the scanning electron micrographs of the corresponding beads at different magnications $(\mathrm{b} \times 50 ; \mathrm{c} \times 2000)$

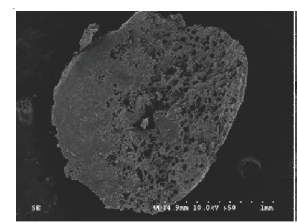

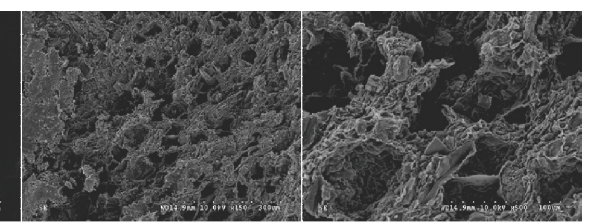

C

Fig. 4. Scanning electron micrographs of cutting plane of the composite beads at different magnications $(\mathrm{a} \times 50 ; \mathrm{b} \times 150 ; \mathrm{c} \times 500)$

Thermogravimetric analysis: The thermogravimetric analysis (TGA) was performed to investigate the thermal stability of the beads. As shown in Fig. 5, the residual weight percentages for SA-BT bead, sodium alginate bead, SA-CS bead and SA-BT-CS bead were 43, 29, 24 and $32 \%$, respectively. In the TGA studies of the thermogram, the temperature

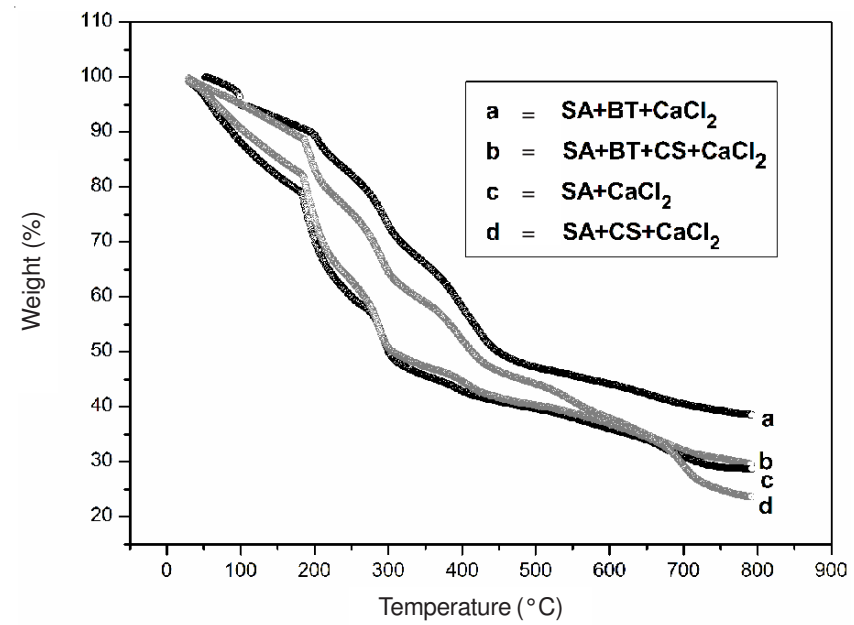

Fig. 5. Thermogram of (a) SA-BT bead, (b) SA-BT-CS bead, (c) sodium alginate bead and (d) SA-CS bead 
range between 40 and $180{ }^{\circ} \mathrm{C}$ corresponded to the loss of absorbed water and bound water interacted with sodium alginate and chitosan. Thermal decomposition of sodium alginate and chitosan began at the temperature between 180 and $440{ }^{\circ} \mathrm{C}$ resulting in the formation of $\mathrm{CO}, \mathrm{CO}_{2}$ and $\mathrm{H}_{2} \mathrm{O}$. In the comparison of all formulations, addition of bentonite could reduce the rate of weight loss. There was few difference between the curve (c) and curve (d). The results presented that chitosan dissolved in the gelling agent only covered at the beads' surface to form a layer of film in the moment of dropping droplets into a bead, which is profitable to enhance the compactness and mechanical strength of the beads. Therefore the chitosan accounts for a small proportion of the beads ingredient.

Pesticide-loading analysis: As shown in Fig. 6, the drug loading rate(DL) and encapsulation efficiency (EE) of 4.16 and $36.36 \%$ obtained from sodium alginate bead were lower than 4.91 and $63.01 \%$ obtained from SA-BT bead and lower than 5.23 and $54.29 \%$ obtained from sodium alginate bead, respectively. These improvement may be obtained depending on the interactions of the components (Fig. 7). The bentonite were promising as carrier materials with large mesopores, prominent adsorption ability and adsorption ability generated by the strength of the polymeric gel network which are effective to incorporate pesticides. At the same time the chitosan could form polyelectrolyte complexes with sodium alginate by electrostatic interaction which was beneficial to improve the drug loading rate (DL) and encapsulation efficiency (EE).

Water uptake: The sodium alginate beads showed an equilibrium swelling of $58 \%$ which decreased with the incorporation of chitosan $44 \%$ and bentonite to $40 \%$ in the beads (Fig. 8). Since sodium alginate and chitosan have a large number of hydrophilic groups, they have extensive water uptake in the water. But polyelectrolyte complexes formed by sodium alginate and chitosan can regulate the swelling of the beads in the water (Fig. 8). Bentonite contains a lot of hydroxyl groups on the surface that could form the hydrogen bonds with the sodium alginate and chitosan, which could effectively inhibit calcium alginate large swelling. As a whole, the beads were

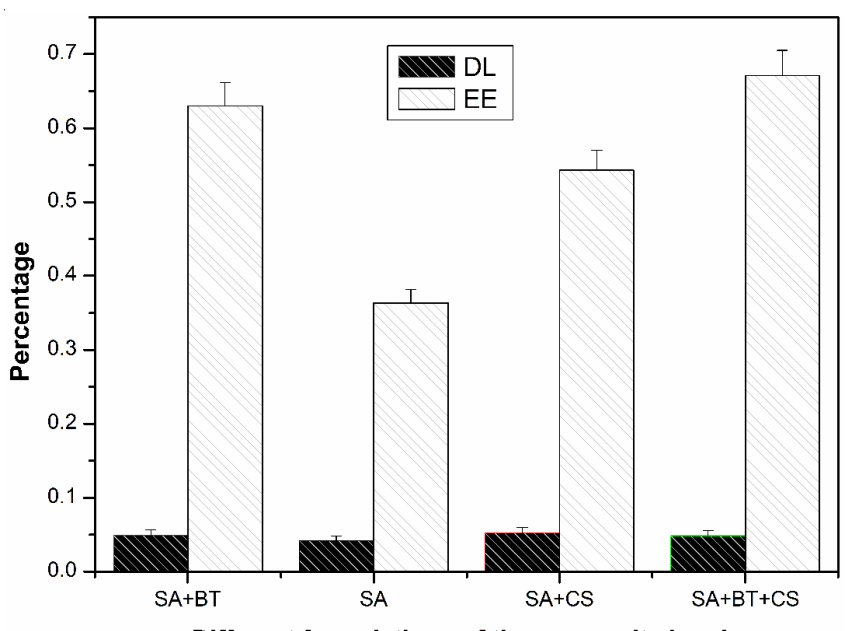

Fig. 6. Drug loading rate(DL) and encapsulation efficiency(EE) of SA-BT bead, sodium alginate bead, SA-CS bead and SA-BT-CS bead (error bars represent the standard deviation of three replicates)

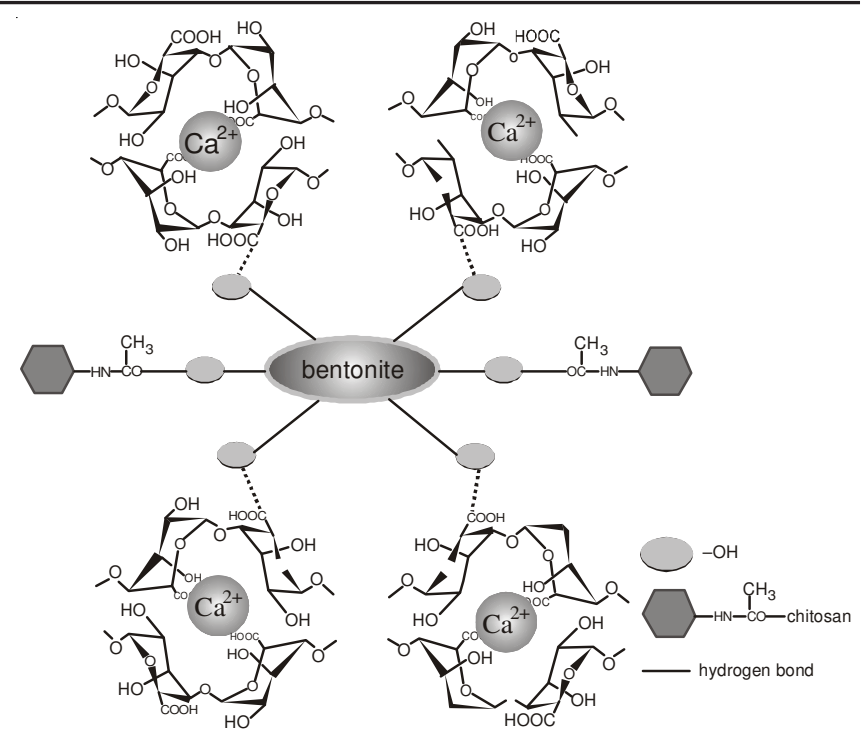

Fig. 7. Schematic diagram for Inhibition of the hydrogel beads' swelling

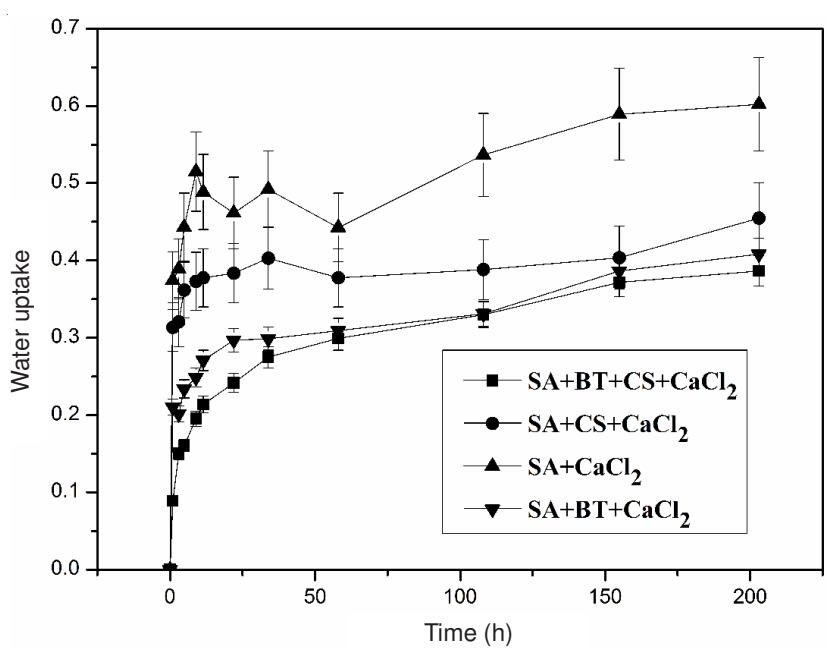

Fig. 8. Water uptake of the SA-BT-CS beads, the sodium alginate beads, the SA-CS beads and the SA-BT beads over time (error bars represent the standard deviation of three replicates)

rapidly swelling at the beginning of $12 \mathrm{~h}$ due to the hydrophilic contents in the beads. Later, they were slowly swelling within $200 \mathrm{~h}$ and still continued until the rupture of the beads.

Release studies: Release of acetamiprid was carried out at the same time that the pesticides diffused out of the mesh of the swelled beads' network. The extensive water uptake properties of the sodium alginate (Fig. 8) resulted in the initial fast release of acetamiprid, which could be alleviated by adding the bentonite or chitosan (Fig. 9). With the addition of bentonite and chitosan, the acetamiprid release rate decreased to some extent. In other words, the decrease of acetamiprid release rate was due to the inherent adsorption capacity of bentonite and the film-forming feature of chitosan. In order to investigate the release rates of the different formulations in depth, a classical model, known as the power law ${ }^{24}$, was used to analyze the release process.

$$
\frac{\mathrm{M}_{\mathrm{t}}}{\mathrm{M}_{\infty}}=\mathrm{Kt}^{\mathrm{n}}
$$

where $M_{t} / M_{\infty}$ is the fractional release of drug in time $t, K$ is a constant incorporating structural and geometrical characteristic 


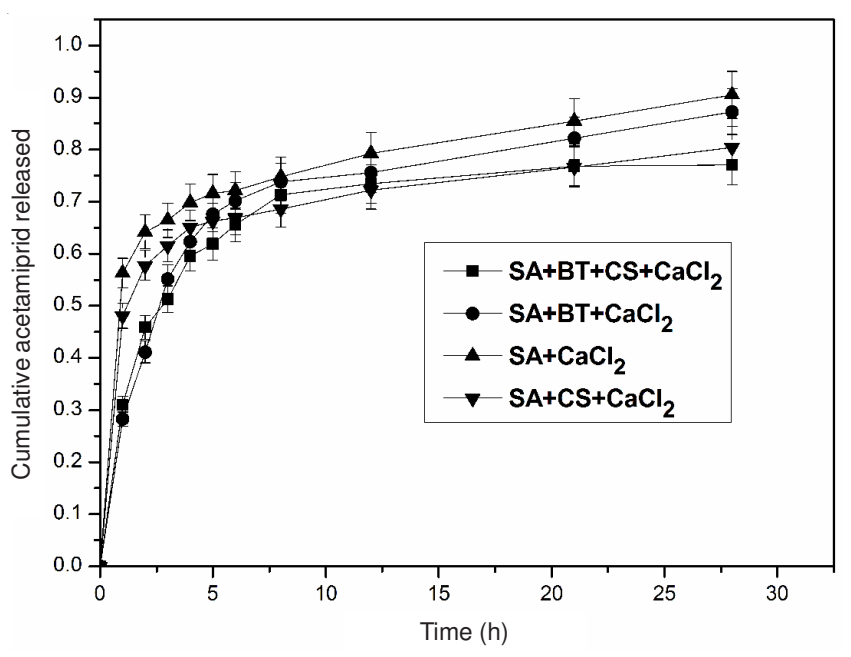

Fig. 9. Release of acetamiprid from the SA-BT-CS beads, the SA-BT beads, the sodium alginate beads and the SA-CS beads (error bars represent the standard deviation of three replicates), respectively

of the delivery system and $\mathrm{n}$ is the diffusion exponent characteristic of the release mechanism.

The model was applied to the analysis of data where $\mathrm{M}_{\mathrm{t}} / \mathrm{M}_{\infty}<0.6$. According to the correlation coefficient $\left(\mathrm{R}^{2}>0.99\right)$ (Table-2), the release of acetamiprid from a variety of formulations was in line with the model equations. The $\mathrm{n}$ value of all formulations ranging from 0.55 to 0.86 was higher than that of bead carrier $(n=0.43)$ and closer to that of the sheet carrier $(n=0.5)$. This deviation was about the relative enrichment of pesticides in the outer layer of the beads. The results may be explained by the fact that the formulations were prepared by the extrusion-exogenous gelation method. The gelling of the beads always started from the outer layer. After a certain time, the outer gelling density should be higher than the inner layer which would cause the relative enrichment of the agrochemical active ingredient in the outer layer.

\begin{tabular}{cccc}
\multicolumn{4}{c}{ TABLE-2 } \\
DIFFERENT FORMULATIONS OF THE \\
\multicolumn{3}{|c}{ ACETAMIPRID RELEASE OF DATA FITTING RESULTS } \\
\hline Formulation code & $\mathrm{k} / \mathrm{h}^{-\mathrm{n}}$ & $\mathrm{n}$ & $\mathrm{R}^{2}$ \\
\hline SA-C1 & $0.2747 \pm 0.0004$ & $0.6117 \pm 0.0084$ & 0.9999 \\
SA-C2 & $0.5180 \pm 0.0007$ & $0.8669 \pm 0.0145$ & 0.9957 \\
SA-C3 & $0.3971 \pm 0.0001$ & $0.7505 \pm 0.0167$ & 0.9901 \\
SA-C4 & $0.2839 \pm 0.0006$ & $0.5547 \pm 0.0095$ & 0.9981 \\
\hline
\end{tabular}

\section{Conclusion}

The drug-loaded hydrogel beads, using bentonite as an adsorbent and film-forming properties of chitosan, were successfully prepared by extrusion into calcium chloride solution. The obtained beads exhibited regularly spherical shapes and uniform sizes with diameters of $1.42 \pm 0.22-1.71$ $\pm 0.25 \mathrm{~mm}$.

Comprehensive analysis of the various experimental results showed that the bentonite, using as a modifier with its own inherent adsorption capacity and structure, not only improved the drug-loading efficiency of the beads and made the drug loading rate (DL) and encapsulation efficiency (EE) of acetamiprid rise up from 4.16 and $36.36 \%$ to 4.91 and $63.01 \%$, respectively, but also effectively inhibited calcium alginate large swelling by hydrogen bonds with the sodium alginate and chitosan to prolong the release of pesticides. The chitosan surrounds the beads' surface to form a layer of film by the electrostatic interactions to improve the toughness of the beads and the drug-loading capacity which improved the drug loading rate and encapsulation efficiency of acetamiprid from 4.16 and $36.36 \%$ to 5.23 and $54.29 \%$, respectively.

\section{ACKNOWLEDGEMENTS}

Financially supported from the Project "The Research and Industrialization of Green Ecological Pesticide" (2011BAE06A06-07, 2011BAEO6B04-7), Plan of Hainan province supported by major scientific and technological projects (ZDXM20120003) and the support from Analytical and Testing Center of Hainan University was gratefully acknowledged.

\section{REFERENCES}

1. M. Fernández-Pérez, M. Villafranca-Sánchez, F. Flores-Céspedes, F.J. Garrido-Herrera and S. Pérez-García, J. Agric. Food Chem., 53, 6697 (2005).

2. F.F. Céspedes, M.V. Sánchez, S.P. García and M.F. Pérez, Chemosphere, 69, 785 (2007).

3. F. Sopena, A. Cavrera, C. Maqueda and E. Morillo, J. Agric. Food Chem., 55, 8200 (2007).

4. O.D. DaileyJr., J. Agric. Food Chem., 52, 6742 (2004).

5. K. Tsuji, J. Microencapsul., 18, 137 (2001).

6. K.S. Soppirnath and T.M. Aminabhavi, Eur. J. Pharm Biopharm., 53, 87 (2002).

7. S.G. Kumbar, K.S. Soppirnath and T.M. Aminabhavi, J. Appl. Polym. Sci., 87, 1525 (2003).

8. W.J. Connick, J.H. Bradow, W. Wells, K.K. Steward and T.K. Van, J. Agric. Food Chem., 32, 1199 (1984).

9. A.B. Pepperman and J.-C.W. Kuan, J. Control. Rel., 26, 21 (1993).

10. R.M. Johnson and A.B. Pepperman, Pestic. Sci., 48, 157 (1996).

11. Manuel Fernández-Pérez, M. Villafranca-Sánchez, E. González-Pradas, F. Martinez-López and F. Flores-Céspedes, J. Agric. Food Chem., 48, 938 (2000)

12. Shengyi Dong, Angew. Chem., 123, 1946 (2011).

13. M.J. Zohuriaan-Mehr and A. Pourjavadi, Polym. Adv. Technol., 14, 508 (2003).

14. C.K. Yeom and K.H. Lee, J. Appl. Polym. Sci., 67, 949 (1998).

15. S.G. Kumbar and T.M. Aminabhavi, J. Appl. Polym. Sci., 84, 552 (2002).

16. Manuel Fernandez-perez, J. Agric. Food Chem., 52, 3889 (2004).

17. B. Singh, D.K. Sharma, R. Kumar and A. Gupta, Appl. Clay Sci., 45, 76 (2009).

18. Yukie Takemoto, Chem. Mater, 22, 2923 (2010).

19. Q.S. Gu and T.F. Xi, Shanghai Second Military Med. Univ. Press, 13, 35 (2006).

20. H.B. Scher, Controlled-Release Delivery Systems for Pesticides, Marcel Dekker Inc., New York (1999).

21. B. Singh, D.K. Sharma and A. Gupta, J. Hazard Mater., 161, 208 (2009).

22. N.M. Franson and N.A. Peppas, J. Appl. Polym. Sci., 28, 1309 (1983).

23. J.S. Yang, H.B. Ren and Y.J. Xie, Biomacromolecules, 12, 2982 (2011).

24. P.L. Ritger and N.A. Peppas, J. Control. Rel., 5, 37 (1987). 